\title{
Governamentalidades e usos de drogas no Brasil
}

\author{
Governmentalities and the use of drugs in Brasil
}

\section{Carlos Eduardo Martins TORCATO ${ }^{1}$ Tiago Magalhães RIBEIRO²}

\begin{abstract}
Resumo: As discussões realizadas por Michel Foucault sobre 'governamentalidade', no final dos anos de 1970 e início dos 1980, têm inspirado análises recentes sobre a questão das drogas na sociedade brasileira. Este artigo pretende apresentar e discutir algumas questões epistemológicas presentes nestas discussões, contrapondo a evolução desse conceito às formas como ele foi apropriado no Brasil. Com base na crítica desenvolvida pela história social em torno de um suposto estruturalismo existente em suas considerações, mostrar-se-á que as reflexões acerca do conceito de 'governo de si' foram uma forma encontrada por esse autor para pensar a relação da agência com as práticas discursivas. Finalizamos apresentando as considerações que o próprio Foucault desenvolveu sobre as drogas a partir das posições epistemológicas apresentadas.
\end{abstract}

Palavras-chave: Governamentalidade. Drogas. Michel Foucault.

Abstract: The discussions held by Michel Foucault on 'governmentality' in the late 1970s and early 1980s have inspired recent reviews on the drug issue in brazilian society. This article aims to present and discuss some epistemological issues present in these discussions, comparing the evolution of this concept to the ways he was recognized in Brazil. Based on the comments developed by social history around a supposed existing structuralism in their considerations, will show that the reflections on the concept of 'government of self ' were a way for the author to think the agency's relationship with discursive practices. We finish presenting the considerations that Foucault himself developed on drugs from presented epistemological positions.

Keywords:Governmentality. Drugs. Michel Foucault.

Submetido em: 21/01/2015. Aceito em: 01/05/2015.

${ }^{1}$ Doutorando em História Social pelo Programa de Pós-Graduação em História Social pela Universidade de São Paulo (USP, Brasil). Apoio Fundação de Amparo à Pesquisa do Estado de São Paulo (FAPESP, Brasil).Email: <carlos.torcato@gmail.com>.

${ }^{2}$ Doutorando em Educação pela Universidade do Vale do Rio dos Sinos (Unisinos, Brasil). Técnico em Assuntos Educacionais no Instituto de Filosofia e Ciências Humanas da Universidade Federal do Rio Grande do Sul (UFRGS, Brasil). Apoio Capes. E-mail: <tiagomribeiro@gmail.com>.

Argumentum, Vitória (ES), v. 7, n.1, p. 39-54, jan./jun. 2015. 


\section{Introdução}

$\mathrm{O}$ presente artigo pretende fornecer elementos que possam contribuir para a incipiente discussão crítica sobre as formas pelas quais, historicamente, as práticas de uso de substâncias psicoativas têm sido objeto de problematização e de governo ${ }^{3}$ em nosso país. Ao longo de mais de cem anos, o Estado vem procurando intervir nessas práticas de consumo com objetivo de excluir algumas substâncias que se convencionou internacionalmente serem prejudiciais à saúde pública. Mas é somente atualmente que se tem questionado a eficácia dos esforços realizados para diminuir o consumo, colocando na pauta pública o tema da nossa relação com as drogas e das formas pelas quais concerne, ou não, ao Estado, e em que medida, interferir nessa

${ }^{3}$ Segundo Foucault (2012, p. 236), "[...] problematização não quer dizer representação de um objeto preexistente, nem tampouco a criação pelo discurso de um objeto que não existe. É o conjunto das práticas discursivas ou não discursivas que faz alguma coisa entrar no jogo do verdadeiro e do falso e a constitui como objeto para o pensamento (seja sob a forma da reflexão moral, do conhecimento científico, da análise política etc.)". Assim, e como reflete Deleuze (2005), é somente através de "problematizações" que o verdadeiro pode ser produzido, sendo as próprias problematizações resultados de práticas de ver e de dizer. Já "governo" é compreendido, aqui, como a ação de governar, uma ação que se dá de modo a conduzir ou dirigir as ações alheias (ou as próprias). Assim, trata-se de compreender o "governo" como condução das condutas dos outros e de si mesmo. Não se restringe, portanto, o uso desse termo, à condução ou direção do Estado, estendendo-se a uma série de outras instâncias sociais que também são governadas, como a família, os alunos, a população, os indivíduos... O governo constitui um tipo de poder, uma forma específica de organização e exercício do poder, a qual tem na "conduta", própria e alheia, o seu objeto. relação, bem como que tipo de interferência seria desejável, correta, eficaz.

Argumentaremos aqui que a reflexão crítica e analítica acerca de como o Estado, os indivíduos, os grupos sociais, em suma "a sociedade" pensa e pratica o controle sobre o uso das drogas tornadas ilícitas pode se beneficiar com a adoção de uma ferramenta analítica cunhada pelo filósofo e historiador francês Michel Foucault (2008a; 2010). Tal ferramenta, chamada pelo autor de "governamentalidade", nos permite compreender a vida social como jogo estratégico através do qual as condutas individuais e coletivas são produzidas como resultado do contato, da imbricação, da relação que se configura e reconfigura, historicamente, entre as maneiras de governar os indivíduos por meio de discursos ${ }^{4}$ e de práticas de poder mais ou menos institucionalizadas, que visam condicionar seu campo de possibilidades de ação, e as maneiras pelas quais os próprios indivíduos governam a si mesmos por meio de técnicas, de exercícios, de investimentos sobre seus "eus", tendo em vista a consti-

"Os "discursos" são aqui compreendidos como elementos centrais em "[...] um jogo complexo e instável em que o discurso pode ser, ao mesmo tempo, instrumento e efeito de poder, e também obstáculo, escora, ponto de resistência e ponto de partida de uma estratégia oposta". Assim, "[...] o discurso veicula e produz poder; reforça-o mas também o mina, expõe, debilita e permite barrá-lo [...]" [uso essa ideia na página 15], de modo que "[...] não existe um discurso do poder de um lado e, em face dele, um outro contraposto. Os discursos são elementos ou blocos táticos no campo das correlações de força [uso essa expressão para fazer o fechamento]; podem existir discursos diferentes e mesmo contraditórios dentro de uma mesma estratégia; podem, ao contrário, circular sem mudar de forma entre estratégias opostas" (FOUCAULT, 2003, p.96-97). 
tuição de certas formas de ser (GROS, 2010).

A utilização dessa grade conceitual para análise da questão das drogas somente atualmente vem sendo realizada (CARVALHO, 2013; RIBEIRO, 2013; RODRIGUES, 2004; ROSA, 2014), acompanhando, de certa forma, o debate que se seguiu às publicações em português das aulas no Collège de France que tratam desse tema (FOUCAULT, 2008a; 2008b). Dado esse caráter ainda incipiente, nosso artigo pretende apresentar e discutir algumas questões epistemológicas presentes nas considerações de Foucault e na apropriação que suas ideias tiveram no Brasil. Não se trata, portanto, de uma revisão bibliográfica.

\section{A delimitação espacial-temporal e o fetiche da teoria}

Quando pensamos as formas como as substâncias psicoativas vêm se tornando objeto de problematização e de governo, é comum remetermos à quase centenária política proibicionista. É traçada uma linha de continuidade entre o passado e o presente, com ênfase no caráter exógeno dessas políticas à realidade brasileira.

Seguindo esse raciocínio, o processo de proibição das drogas teria iniciado a partir da realização, em Xangai, na China, no ano de 1909, da Primeira Conferência Internacional do Ópio. Essa conferência foi seguida de uma série de outras (sendo as mais importantes realizadas em Haia, na Holanda, entre 1911 e 1912, e em Genebra, na Suíça, nos anos de 1925, 1931 e 1936) e instituiu recomendações de controle sobre substâncias como o ópio e a cocaína, bem como sobre seus derivados. O Brasil foi signatário de todas as convenções a partir da Convenção de Haia, a qual foi ratificada pelo governo em 1913 e promulgada por meio do decreto $n^{\circ}$ 11.481, em 1915, tendo entrado em vigor, contudo, somente a partir de 1921, quando passou a vigorar a Lei no 4.294/1921 (CARVALHO, 2013, p. 26). A maconha, no entanto, só teve seu uso penalizado por lei federal no ano de 1932 (SOUZA, 2012, p. 35). O Brasil não teria participado ativamente da construção dessa política nos foros internacionais, posição que "[...] parecia a princípio se justificar. Com efeito, o país se manteve em grande medida incólume ao problema das drogas durante décadas" (SILVA, 2013, p. 91).

A primeira droga cujo uso foi problematizado como doença, no Brasil, foi o álcool, através do conceito de alcoolismo, no século XIX (SANTOS, 1993; 1995; 2006). Apesar de usarem exemplos que remetiam à realidade local, os médicos brasileiros "[...] reproduziam por aqui os mesmos paradigmas que embasavam a prática médica na Europa" (SANTOS, 1995, p. 56). Teorização que se mostrava complicada, pois eles preservavam "[...] demasiada fidelidade ao pensamento original, fora da realidade brasileira" (SANTOS, 1995, p. 56). Igualmente como ocorre na leitura sobre o processo de implementação do proibicionismo no Brasil, são as práticas discursivas elaboradas em contextos externos que são predominantes na definição da problemática das drogas.

A mesma ênfase no caráter exógeno das práticas discursivas também pode ser percebida na adoção do conceito de governamentalidade, como o praticado por Rosa 
(2014). Segundo este autor, a política de redução de danos se circunscreve como uma biopolítica que normatiza os indivíduos por meio de dispositivos de normatização e de segurança, transformando exusuários em profissionais da saúde remunerados. Esses indivíduos "[...] governamentalizaram o 'empreendedorismo de si', passando a racionalizar o chamado marketing pessoal proposto pela Teoria do Capital Humano" (ROSA, 2014, p. 83). Os redutores de danos internalizariam pressupostos desta teoria, que é elaborada em terras estadunidenses, adotando a partir de então uma racionalidade neoliberal.

Esses três exemplos mostram como a problemática das drogas tem sido pensada, para compreender a realidade brasileira, a partir de contextos e de práticas discursivas exógenas a esta realidade. Foi com base nas configurações históricas de exercício de poder na Europa que Foucault aponta para o desenvolvimento de uma forma específica, o biopoder, no século XVII, descrevendo-o como um tipo de poder que se exerce sobre dois polos. No primeiro polo, ele se exerce como uma anátomo-política do corpo humano e procura maximizar as forças do indivíduo, ajustando-o a regimes de produção e potencializando sua eficiência. Nesse polo, o corpo é individualizado, adestrado, buscando-se o "[...] crescimento paralelo de sua utilidade e docilidade, na sua integração em sistemas de controle eficazes e econômicos" (FOUCAULT, 2003, p. 131). Já no segundo polo, que se desenvolve mais tarde, por volta da metade do século XVIII, o biopoder se exerce como uma "biopolítica da população": ele investe sobre os fenômenos da vida do corpo humano coletivo enquanto espécie, intervindo nos processos de nascimento, morbidade, mortalidade, longevidade, nível de saúde, no sentido de dispor da vitalidade da população como um recurso mediante controles e intervenções voltadas à maximização da vida. Trata-se, nos dois casos, da produção de indivíduos e de uma população normalizados, produtivos, saudáveis, úteis economicamente e dóceis politicamente às finalidades de perpetuação, desenvolvimento e fortalecimento do Estado e das forças políticas, econômicas e sociais que o atravessam, estabilizam e constituem. Voltado à obtenção da sujeição dos corpos e ao controle das populações, o biopoder informa uma série de disciplinas e técnicas orientadas "[...] pela administração dos corpos e pela gestão calculista da vida [...]": escolas, colégios, casernas, demografia, saúde pública, saneamento, estatística são invenções moldadas pelo exercício institucionalizado desse poder que marca "[...] a entrada dos fenômenos próprios à vida da espécie humana na ordem do saber e do poder - no campo das técnicas políticas" (FOUCAULT, 2003, p. 133).

Importante ressaltar que as pesquisas realizadas por Foucault (2003; 2008a; 2008b) se utilizaram de fontes documentais concernentes a alguns países europeus (principalmente França, Inglaterra e Alemanha) e a uma época bastante precisa (chamada por ele de "clássica" - entre os XVII e XVIII). A noção de biopolítica procura produzir elos explicativos entre processos históricos semelhantes que se davam, naquele contexto e naqueles países, em torno de novas formas de definir e de atuar sobre a população, tomada, pela primeira vez, como um objeto vivo cuja naturalidade e recorrências podiam ser mapeadas e, até certo ponto, 
condicionadas. Essa politização de aspectos da vida da população enquanto espécie, tendo em vista a maximização de suas forças para usufruto do Estado (e, colateralmente, para usufruto dos próprios indivíduos e coletividades, que tinham sua saúde e sua qualidade de vida maximizadas) acabou constituindo um elemento fundamental para as estratégias modernas de administração das populações por parte dos Estados Nacionais, disseminando-se, ao longo dos últimos dois séculos, por diferentes regiões.

É forçoso notar, nesse processo, quais foram os diferentes aspectos e as forças políticas, econômicas, sociais, morais que se fizeram (e se fazem) atuantes. As diferenças de época, de cultura e de forças em ação fazem com que não seja possível simplesmente transpor o circunscrito fenômeno estudado por Foucault a partir da análise de processos particulares para todo e qualquer processo histórico no qual aspectos da vida da população enquanto espécie são tornados objetos de racionalizações e de intervenções políticas as mais diversas. É nesse sentido que, inspirados na noção de formações biopolíticas (COLLIER, 2011a; 2011b), argumentamos sobre a necessidade de buscar o processo histórico-cultural pelo qual vem se constituindo a tomada da população como objeto de intervenções políticas. Essas especificidades precisam ser conhecidas a partir dos materiais empíricos locais, mesmo que esse processo se ancore ou se inspire em práticas acionadas em outros países e contextos. Ela parece mais profícua para a descrição e a análise de processos que, bastante afastados no tempo e no espaço daqueles descritos e analisados por Foucault, apresentam-se como formas específicas nas quais a vida biológica (mas também a vida econômica e a vida social da população) é tornada objeto de reflexões e de intervenções políticas.

A ênfase na delimitação temporal e espacial permite uma maior sensibilidade às correlações de forças, evitando assim uma leitura estruturalista que generaliza determinados elementos táticos/estratégicos para o todo social. É típico da leitura estruturalista transpor os modelos explicativos e conceituais sobre o objeto de pesquisa, substituindo os conceitos pelas evidências. É o fetiche da teoria que seduzia muitos marxistas, como Louis Althusser, e que era tão criticado por Foucault. Paradoxalmente, este autor tem inspirado leituras que tendem a "transcendentalizar" análises cuja eficácia e força explicativa residem, precisamente, em uma historicidade pouco considerada.

É prudente, quando se utiliza os conceitos foucaultianos, identificar, descrever e analisar de forma localizada e particularizada o tema que está sujeito à análise. Assim, quando se trata de descrever elementos da constituição das governamentalidades dos usos de drogas no Brasil, o que cabe fazer é buscar compreender de que modos foram problematizados, em nosso país, os comportamentos das pessoas que faziam uso dessas substâncias quando elas se tornaram foco de preocupações e, consequentemente, de intervenções. Trata-se, portanto, de compreendermos uma formação biopolítica específica mediante uma análise contextual acerca de como o uso dessas substâncias foi constituído enquanto problema pensável e administrável, como essa administração desse problema vem sendo construída, co- 
mo respostas particulares, locais, a esse problema vêm sendo dadas e, também, de como esses movimentos têm impactado os processos de constituição de sujeitos usuários de drogas.

\section{A crítica da história social ao estruturalis- mo foucaultiano}

A ênfase nos contextos e nas práticas discursivas locais serve como uma forma de prudência metodológica que evita a supremacia teórica sobre as evidências empíricas. O pensamento da década de 1970, que inclui o próprio Foucault, foi exemplar na crítica ao estruturalismo que dominava o pensamento das décadas anteriores, principalmente o marxismo ortodoxo soviético que influenciava as esquerdas políticas. Procuraremos mostrar como esse debate foi apropriado, no interior do campo historiográfico brasileiro, dando ênfase à crítica epistemológica desenvolvida pela história social às pesquisas entendidas como foucaultianas.

A relevância política do marxismo como plataforma de ação que pautava os grupos de esquerda, em todo o mundo, depois dos conflitos mundiais, colocava para os intelectuais marxistas os problemas decorrentes do fetiche da teoria. Vários pensadores se colocaram contra essa pretensão colonizadora que tendia a criar categorias teóricas que deviam, ao invés de problematizadas, ser confirmadas pelas evidências. Na história, a crítica desenvolvida por Thompson (1981) levou a uma leitura renovada do conceito de classe e outros, não como categorias pré-existentes onde se encaixam os objetos de análise, mas sim como realidades construídas a partir das experiências coleti- vas dos sujeitos concretos (THOMPSON, 1987). Considerações que estão na base de toda uma geração de historiadores conhecidos como marxistas britânicos (KAYE, 1989) e que, ao lado das abordagens francesas sobre o cotidiano, tiveram enorme influência na historiografia nacional a partir da sua profissionalização na década de 1980. É a famosa "[...] história vista de baixo" (CASTRO, 1997, p. 49-50).

Paralelamente a essa leitura renovada do marxismo se percebe a introdução e a consolidação da influência das obras de Michel Foucault, no Brasil, em vários campos do conhecimento, entre eles na história. $\mathrm{O}$ foco dessas análises que enfatizavam o poder de subjetivação dos discursos criou uma percepção de conflito e de dinâmica histórica "[...] produzida em nível simbólico" (CASTRO, 1997, p. 52). Perspectiva que se opôs à ideia de que os sujeitos são formados a partir da experiência, pois eles seriam "[...] compreendidos antes como produções (criações) de práticas discursivas (ou simbólicas) concorrentes e não como produtos sociais efetivos da experiência histórica" (CASTRO, 1997. p. 52). Tal leitura tornou hegemônica e colocou em lados opostos os(as) historiadores(as) sociais e aqueles que denominaremos de "foucaultianos(as)". É nosso propósito relativizar essa cisão a partir das concepções apresentada por Foucault nos cursos do Collège de France que discutiram o biopoder - e que só foram traduzidos para o português em 2008.

A separação entre práticas discursivas, formadoras de subjetividades, e a experiência histórica de sujeitos concretos, como defende Castro (1997) acima, parece colocar sobre as práticas discursivas os mesmos 
efeitos autoexplicativos que outrora eram atribuídos à infraestrutura no marxismo ortodoxo. Contrariamente, para Foucault, a análise do biopoder é uma história do Estado baseada "[...] a partir da própria prática dos homens, a partir do que eles fazem e da maneira como pensam" (FOUCAULT, $2008 b$, p. 481). Análise que é possível porque "[...] não há, entre o nível do micropoder e o nível do macropoder, algo como um corte" (FOUCAULT, 2008b, p. 481). Por isso "[...] uma análise em termos de micropoderes compatibiliza-se sem nenhuma dificuldade com a análise dos problemas como o do governo e do Estado" (FOUCAULT, 2008b, p. 481). Os aparelhos de governo e os saberes que o sustentam não são meramente simbólicos, eles precisam ser confirmados a partir da própria prática dos sujeitos e não o inverso. É nesse sentido que Foucault também precisa ser compreendido como um crítico ao estruturalismo.

Não foi, entretanto, como uma crítica ao estruturalismo que seu pensamento influenciou a historiografia brasileira. Os autores (MACHADO et al, 1978; COSTA, 1979) que introduziram seu pensamento na historiografia brasileira formularam uma potente crítica à história da medicina tradicional caracterizada por uma perspectiva evolucionista centrada na atuação dos médicos oficiais de tradição hipocrática:

[...] tendo a saúde como fio condutor da análise da sociedade, a medicina que se impôs desde o século XIX - esquadrinhando o espaço urbano, inventariando o positivo e o negativo, as potencialidades e os recursos e propondo um programa normatizador do indivíduo e da população - penetra em tudo e inclusive no aparelho de Estado. Relação que não é de jus- taposição ou de apropriação, mas de imanência (MACHADO et al., 1978, p. 157).

Foi contra essa pretensão de um poder que penetra em tudo, que normatiza indivíduos e que se confunde com o próprio Estado que toda uma crítica se construiu a partir da história social. Edler (1992) reconstituiu as reformas do ensino médico (1854 e 1884) demonstrando as disputas existentes no interior da medicina acadêmica e com as outras formas de cura. Sayd (1998) mostrou o ceticismo terapêutico nascido da inadequação dos remédios disponíveis com a emergência da noção de doença como ser ontológico. Schwarcs (1993) demonstrou a abrangência da questão racial entre os cientistas, em geral, e entre os médicos em particular. Chalhoub (1996) focou nos conflitos nascidos das reações e das resistências populares às práticas oficiais de cura, principalmente a vacina. Benchimol (1999) estudou a geração de bacteriologistas brasileiros que tornou a medicina do país um polo dinâmico de produção nesse campo. Luz (1996) reconstituiu a trajetória da homeopatia e as batalhas entre eles e os médicos alopáticos de tradição hipocrática.

Os autores influenciados por Foucault veriam “[...] nessa medicalização, no domínio da Ordem Médica, um massacre, onipresente e coerente" (SAYD, 1998, p. 151). Um poder que "[...] impedia a relação médicopaciente, ao se interpor como uma instituição abstrata a dominar todo o saber, instituição plena de normas impessoais cuja finalidade única é a disciplina, jamais o prazer ou a alegria de viver" (SAYD, 1998, p. 151). Essa instituição médica entendida como total 
[...] comete, ao nosso ver, os equívocos da generalização e da simplificação, por acreditar nos mitos denunciados por Foucault. Efetivamente, os médicos fazem um discurso público onde se apresentam como cientistas e praticantes de uma atividade inteiramente normatizada segundo cânones científicos, portanto homogênea. O mais elementar bom senso mostra, entretanto, a impossibilidade dessa prática, ou a mera observação revela amplamente a sua inexistência (SAYD, 1998, p.152).

Procuramos mostrar, ao longo deste artigo, como a ênfase no poder normatizador das práticas discursivas pode levar a uma leitura estruturalista da teoria foucaultiana. Conforme veremos abaixo, Foucault promoveu deslocamentos teóricos na sua concepção de governamentalidade como forma de responder àqueles que o caracterizavam como estruturalista. Pelo contrário, ele precisa ser compreendido como um dos críticos que contribuíram para a crise geral do estruturalismo na década de 1970. É preciso destacar que os autores (MACHADO et al., 1978; COSTA, 1979) que introduziram o pensamento foucaultiano eram contemporâneos ao próprio autor - que estava em plena construção de sua produção intelectual.

O conceito de governamentalidade não foi apresentado de forma sistematizada (livro), fato que certamente dificultou e atrasou os debates a seu respeito. Esse conceito foi alvo de intensas discussões no Collège de France entre o final da década de 1970 e o início dos anos de 1980, quando ocorrem alguns deslocamentos na definição dessa noção. Por se tratar de excertos (aulas) é possível identificar diferentes significados ao longo de suas obras, com vieses variados para sua compreensão. Em 1978, no curso intitulado Segurança, Território e População, ele descreveu a "governamentalidade" como uma noção metodológica profícua para a análise de um conjunto de instituições, procedimentos, cálculos e táticas que permitem exercer, a partir de uma lógica econômica e por meio de dispositivos de segurança, um tipo específico de poder que tem por alvo não mais o indivíduo, como era o caso do poder disciplinar, mas a população (FOUCAULT, 2008a). Nesse sentido, o sujeito emerge como ponto terminal, como resultado desse processo de investimentos de poder por meio de saberes, de instituições, de técnicas e procedimentos. A partir de 1980, entretanto, e até a sua morte, em 1984, Foucault complexificou essa noção, compreendendo-a como a superfície de contato em que se juntam a maneira de conduzir os indivíduos e a maneira pela qual eles se conduzem a si mesmos (GROS, 2010). Aqui, o sujeito não é o produto passivo de poderes e saberes, sendo encontrado no cruzamento instável, variável e, sobretudo, historicamente datável entre tecnologias de dominação e tecnologias do $\mathrm{eu}^{5}$.

${ }^{5}$ Foucault (2004, p. 323-324) entende que os seres humanos desenvolveram diferentes conjuntos de técnicas por meio das quais procuraram constituir formas de conhecimento sobre si mesmos e sobre o mundo. Esses conjuntos são por ele agrupados em quatro grandes "tecnologias", cada uma delas constituindo "[...] uma matriz de razão prática": "[...] (1) tecnologias de produção, que permitem produzir, transformar ou manipular as coisas; (2) tecnologias dos sistemas de signos, que permitem utilizar signos, sentidos, símbolos ou significação; (3) tecnologias de poder, que determinam a conduta dos indivíduos e os submetem a certos fins ou dominação, objetivando o sujeito; (4) tecnologias de si, que permitem aos indivíduos efetuar, com seus próprios meios ou com a ajuda de outros, um certo número de operações em seus próprios corpos, almas, pen-

Argumentum, Vitória (ES), v. 7, n.1, p. 39-54, jan./jun. 2015. 
Sua produção dos anos de 1980 procurava aprofundar a compreensão do papel dos agentes na sua própria subjetivação.

Se governamentalidade for entendida como uma superfície de contato entre governo de si e governo dos outros poderemos compreender como usuários de substâncias psicoativas tornadas ilícitas se constituem em objetos de saberes e de poderes, por um lado, e como esses agentes se constituem a si mesmos como sujeitos usuários de substâncias psicoativas, por outro. Levando um pouco adiante as formulações de Foucault (2012); Miller e Rose (2012) oferecem importantes desenvolvimentos para o conceito de "governamentalidade", os quais contribuem para que o investigador possa tornar mais operacional essa noção, fazendo-a efetivamente funcionar como ferramenta teórica útil para a compreensão de um fenômeno social complexo como é o uso de drogas ilícitas. Segundo esses autores, devemos falar em "governamentalidades", pois se trata "[...] tanto de mentalidades quanto de tecnologias, tanto formas de pensar quanto instrumentos de intervenção" (MILLER; ROSE, 2012, p. 32), estando todas essas dimensões irredutivelmente ligadas umas às outras, conformando íntimas e intrincadas relações de interdependência.

Colocando-se no tempo e no espaço, ou seja, de forma datável e situável, essas "governamentalidades dos usos de drogas"

samentos, conduta e modo de ser, de modo a transformá-los com o objetivo de alcançar um certo estado de felicidade, pureza, sabedoria, perfeição ou imortalidade". A "governamentalidade" constitui, nesse sentido, o campo de contato entre as tecnologias de poder, ou de dominação, e as tecnologias de si ou do eu, campo este a partir do qual se estruturam as relações do ser consigo mesmo. conformam, assim, um campo histórico instável, marcado por rupturas e por retomadas, permanências e transformações, e que deve ser analisado em suas particularidades locais, uma vez que cada contexto histórico e cultural produz modos peculiares de composição entre formas de pensar e instrumentos de intervenção, constituindo, assim, enfrentamentos e relações singulares e produzindo formasde governamentalidades particulares que são atravessadas por forças que precisam ser mapeadas e compreendidas em função das características dos processos políticos, econômicos, culturais, sociais, históricos e morais do local e do tempo nos quais emergem. É a partir dessa noção dinâmica de constituição das subjetividades que a noção de conflito ganha uma nova configuração.

\section{Drogas e governamentalidade}

A viabilidade destes pressupostos teóricos para a análise da questão das drogas pode ser avaliada no fato de o próprio Michel Foucault fazer considerações a esse respeito. Uma pequena reconstituição dessas considerações e a comparação com algumas apropriações nacionais do conceito de governamentalidade serão úteis na elucidação da crítica epistemológica apresentada.

Os escritos sobre drogas estão inseridos na pesquisa sobre os modos como o liberalismo se constituiu enquanto um saber que influenciava as formas políticoinstitucionais de governo. Uma pesquisa que pretendia compreender o processo de mudança do governo como uma prática imposta aos governados pelos que governam (por meio da administração policial), para outra, na qual o foco deixaria de ser os 
próprios sujeitos para se tornar a administração dos seus interesses (FOUCAULT, 2008b, p. 61-64). Como ilustração, cabe um paralelo com suas reflexões sobre a loucura. Inicialmente, a psiquiatria também estava ligada a mecanismos de jurisdição de tipo policial. Foucault reconstituiu quais foram as condições necessárias para que os discursos médicos emitidos sobre essa questão pudessem alterar a forma como tal comportamento era interditado. Sobre as instituições penais, a prática jurisdicional também se alterou com a introdução do pensamento utilitário na reflexão sobre as vantagens e desvantagens das penalidades aplicadas a partir de uma lógica política pautada nos termos da soberania. Sua análise sobre a governamentalidade, portanto, segue com o objetivo de mostrar como o mercado se tornou um princípio de inteligibilidade para o governo ao longo do século XX (FOUCAULT, 2008b, p. 41-51).

Sua abordagem não é exaustiva e se limita ao ordoliberalismo alemão e ao neoliberalismo estadunidense. Este último é concebido como a forma de governo que levou os princípios do mercado a suas últimas consequências - aplicando-os como grade de inteligibilidade para entender as relações sociais como um todo. A questão das "drogas" é levantada justamente para mostrar o equívoco de pensar a criminalidade e a justiça criminal em termos puramente econômicos. Para os neoliberais o crime é definido como qualquer "[...] ação que o indivíduo comete assumindo o risco de ser punido pela lei" (FOUCAULT, 2008b, p. 346). Nessa definição fica implícita a ideia de que as pessoas que fazem a ação criminosa esperam lucrar com seus atos, aceitando os riscos gerados pela lei. O sistema de justiça criminal, nessa concepção, não deve se preocupar com o crime ou com o criminoso, e sim intervir no ambiente para que os riscos com a conduta criminosa não compensem os lucros. Cabe ao poder público, nessa governamentalidade neoliberal, ampliar os mecanismos de controle (Enforcementoflaw) com objetivo de criar maiores riscos e desmotivar os atos criminosos. É um controle que pretende maior eficácia das instituições encarregadas de detectar e punir os crimes (FOUCAULT, 2008b, p. 346-347).

O Enforcementoflawnão pode ser considerado neutro nem indefinidamente extensível por duas razões: quanto maior for a repressão, maior são os riscos e as possibilidades de ganho com a atividade criminosa; e a política penal não pode visar o desaparecimento do crime porque essa situação geraria problemas de ordem social e política - é necessário uma criminalidade em certo patamar porque é inconveniente que a sociedade esteja submetida a um sistema disciplinar exaustivo como era o governo policial (FOUCAULT, 2008b, p. 347-350). A questão das "drogas" é apresentada nesse contexto para mostrar a inviabilidade do neoliberalismo como política penal.

A política de interdição das drogas, adotada a partir dos anos 1960 e inspirada nesses princípios, "[...] visava essencialmente reduzir a oferta de droga" (FOUCAULT, 2008b, p. 351), porém o desmantelamento do comércio ilícito foi apenas parcial gerando três consequências para o mercado: aumentou o preço das drogas; beneficiou e fortaleceu a situação de monopólio e oligopólio dos grandes traficantes e distribuidores; o consumo não diminuiu porque “[...] o drogado vai querer encontrar sua 
mercadoria e estará disposto a pagar qualquer preço por ela" (FOUCAULT, 2008b, p. 351) criando uma inelasticidade da demanda pelo produto. Por isso, o "[...] estilo de enforço (sic) da lei que havia sido desenvolvido no decorrer dos anos 1960 revelouse um fracasso sensacional" (FOUCAULT, $2008 b$, p. 351). A solução para esse fracasso seria uma intervenção no mercado através do fornecimento de psicoativos aos habituados com preços baixos e aos iniciantes a cobrança de altos valores como forma de inibir o consumo. Exatamente o contrário da política de preços utilizada pelos traficantes ilícitos (FOUCAULT, 2008b, p. 351353).

Essas considerações sobre a limitação do neoliberalismo como política penal mostram que a dieta psicoativa da população pode ser um objeto de interesse da governamentalidade dominante e de práticas sociais que impõem desafios aos mecanismos de controle social que são implementados. Cabe pensar, portanto, tanto em quais eram as práticas sociais que ocorriam em torno dos psicoativos (com sujeitos e seus códigos culturais), quanto como era pensada a intervenção sobre elas (produzindo novas e diferentes formas de dominação e de resistência).

Essa perspectiva apresentada acima percebe a governamentalidade como constituída por uma racionalidade de governo e por tecnologias políticas que têm por objeto de intervenção a população, intervenção esta que induz, consequentemente, à elaboração e reelaboração de racionalidades e práticas de resistência (pois se trata de compreender a governamentalidade como um cruzamento instável, variável e, sobretudo, histori- camente datável entre tecnologias de dominação e tecnologias do eu). Essa leitura é diversa daquilo que vem sendo apresentado pela bibliografia. Vejamos alguns exemplos.

Carvalho (2013) procurou:

[...] identificar os mecanismos de poder e os dispositivos que produzem e mantêm os 'assujeitamentos' e forjam subjetividades. Utilizando como materialidade as técnicas e táticas que permitiram centralizar as ações políticas sociais sobre drogas em uma organização governamental [...], a hipótese central dessa dissertação está em propor que a Comissão Nacional de Fiscalização de Entorpecentes (CNFE) se constituiu em um instrumento centralizador, destinado a internalização de um tipo específico de racionalidade [...] (CARVALHO, 2013, p. 24).

São mecanismos de poder que "assujeitam e forjam subjetividades" a partir de "técnicas e táticas". Ênfase bastante parecida com aquela feita por Rodrigues (2004) - o Estado utiliza as drogas como pretexto para ampliar a intervenção sobre hábitos e forjar condutas em seus detalhes: "[...] trata-se da invenção de uma biopolítica que coordena o cotidiano dos indivíduos valendo-se de inúmeras técnicas que visam disciplinar detalhes da conduta de todos e de cada um" (RODRIGUES, 2004, p. 22). Ele também procurou, ao longo de toda a primeira parte do seu livro, perceber o momento em que as práticas proibicionistas " [...] são percebidas pelos mecanismos de governamentalidade como úteis politicamente para ampliar a capacidade estatal de regulação da conduta dos homens" (RODRIGUES, 2004, p. 35). 
É possível perceber, nos excertos colocados acima, que os autores descrevem seus objetos considerando tão somente o primeiro eixo da governamentalidade. Embora eles tenham contribuído para o debate com novas descrições e análises, estas ainda estão demasiadamente focadas nas tecnologias de dominação e fazem (ainda que inadvertidamente) os sujeitos parecerem produções passivas, efeitos e resultados do poder que sobre eles se exerce (ou meros repetidores desse poder 'dos outros' sobre si mesmo).

O próprio Foucault (2008b, p. 102-103) parece ser um crítico do superdimensionamento da influência das elites ou das instituições. Segundo ele, para entender o "[...] operador de transformação [...] será na população que devemos procurá-lo. Não na forma que consistiria em dizer: as classes dirigentes, compreendendo por fim a importância da população, lançaram nessa direção" (FOUCAULT, 2008b, p. 102) outros campos do conhecimento com objetivo de conhecê-la. "Não é dessa forma, mas da forma seguinte: é um jogo incessante entre as técnicas de poder e o objeto destas que foi pouco a pouco recortando no real, como campo de realidade, a população e seus fenômenos específicos" (FOUCAUT, 2008b, p. 103).

A população ou as pessoas nela inseridas não são sujeitos passivos, objetos de uma estratégia de poder elaborada pelas elites políticas ou difundida por uma instituição. Entre as técnicas de poder e seu objeto, no caso a população, é estabelecido um complexo jogo onde as relações sociais de dominação e de resistência alteram a realidade e as relações nela estabelecidas. O grande desafio que se coloca no estudo da questão das drogas a partir da perspectiva da governamentalidade é mostrar como os sujeitos tornam esses poderes seus, o que envolve sempre agência e liberdade - ainda que por vezes em margens bastante exíguas de realização.

\section{A dissidência farmacológica}

Partindo da discussão apresentada, propomos a perspectiva que a experiência do uso de drogas não se esgota nesse processo de descrição e normatização por práticas mais ou menos institucionalizadas e discursos com efeitos de poder. Como enfatiza Michel Foucault (1995, p. 234), devemos analisar as relações de poder não do ponto de vista da sua racionalidade interna, mas através do antagonismo das estratégias. É nas formas como os indivíduos e os grupos que utilizam essas substâncias se relacionam com as racionalidades e com as tecnologias que se encontra a chave de inteligibilidade para compreensão das formas de condicionamento das relações consigo mesmo e com o mundo.

Da forma como a governamentalidade tem sido compreendida, o usuário de drogas ilícitas é pensado como "[...] sendo paulatinamente capturado por meio dos discursos e das práticas [...]" (ROSA, 2014, p. 23) graças à disseminação de noções como risco, vulnerabilidade, qualidade de vida, etc. Essas noções serviriam de base para o desenvolvimento de tecnologias de poder que “[...] acabaram capturando os indivíduos por meio de verdades construídas, sobretudo, pelo saber médico que passam a serem incorporadas por instituições internacionais através dos Direitos Humanos, governamentalizando a população mundial" (RO- 
SA, 2014, p. 23). Tais conceitos funcionariam como justificativa para a intervenção. As técnicas judiciárias e médicas seriam responsáveis por transformar pessoas em "[...] capital humano e, portanto, em sujeitos produtivos para a sociedade" (ROSA, 2014, p. 24). Nesse sentido, os(as) redutores(as) de danos funcionariam como vigilantes dos hábitos dos(as) usuários(as) não apenas nas clínicas, mas também nos locais de consumo, difundindo assim o biopoder. Ao promover o maior controle sobre as formas de consumo, os (as) usuários (as) e ex-usuários (as) conseguem transformar suas atividades, antes ilegais e impuras, em forma de obter vantagens financeiras, sem reconhecer "[...] os assujeitamentos e sujeições em que estão inseridos a partir da racionalidade neoliberal, difusora de capturas" (ROSA, 2014, p. 24).

Procuramos, contrariamente, enfocar nas formas de relacionamento dos indivíduos ou de grupos populacionais - com as racionalidades e tecnologias. Assim, o consumo de substâncias psicoativas (as ilícitas principalmente, mas também consumos autodestrutivos de drogas lícitas) passa a ser entendido como prática social que impõe uma série de desafios à governamentalidade dominante. Esse parece ter sido o sentido que Foucault deu para o fenômeno do consumo e do comércio de drogas perante a racionalidade neoliberal.

Levando em consideração essa posição, propomos uma breve discussão teórica sobre como Foucault problematiza a forma de denominar as resistências geradas por determinadas formas de domínio.
A palavra revolta não the parece adequada para designar o jogo complexo e instável no qual o discurso tem papel de instrumento e efeito de poder, por um lado, ponto de resistência e de obstáculo, por outro, porque ela é " [...] ao mesmo tempo demasiado precisa e demasiado forte para designar certas formas de resistências mais difusas e muito mais suaves" (FOUCAULT, 2008a, p. 263). A palavra desobediência é "[...] sem dúvida fraca demais" (FOUCAULT, 2008a, p. 264). Dissidência, por sua vez, também não lhe agrada porque existe a conotação política que a associa aos opositores internos do comunismo soviético. Por isso ele prefere a expressão "contracondutas", por serem posturas que se opõem àquelas pensadas pela governamentalidade dominante (FOUCAULT, 2008a, p. 264).

Esse debate conceitual apresentado acima foi proposto na análise da crise do poder pastoral cristão, em fins da idade média, fato que marcou a emergência das primeiras formas de governamentalidade marcadas pela razão de Estado - na qual a população deveria ser disciplinada com objetivo de fortalecer o Estado (FOUCAULT, 2008a, p. 144-145). As principais contracondutas no contexto pastoral eram o asceticismo, a horizontalidade de certas comunidades religiosas, os místicos e seu acesso privilegiado às verdades sagradas, a difusão da escritura sagrada e a crença escatológica (Jesus voltará como verdadeiro pastor) (FOUCAULT, 2008a, p. 268-283). Governamentalidade não parece, portanto, algo monolítico construído pelo poder simbólico emanado do discurso/saberes que cresce infinitamente criando subjetividades - é antes de tudo uma disputa política que envolve condutas cotidianas (asceticismo, horizon- 
talidade política, experiências de êxtase), práticas discursivas (crença escatológica, discurso ascético) e configurações institucionais (imprensa).

A análise dos controles políticos estabelecidos sobre as substâncias psicoativas, no início do século $X X$, nos coloca o desafio de pensar tais controles não apenas como uma força institucional nascida de um saber/poder que domina tudo, mas também como produtor de novas e diferentes formas de dominação e de resistência. Propomos nesse artigo a utilização do termo "dissidência" ao invés de "contraconduta" por dois motivos: $1^{\mathrm{o}}$ Passados mais de vinte anos da queda do muro de Berlim, tal associação entre o termo dissidência e a perseguição política soviética não tem mais sentido; 2º Escohotado (2008, p. 665-667) sugere a utilização do termo dissidência porque originalmente o movimento proibicionista internacional teve um impulso decisivo do conservadorismo religioso em matéria de alteração da consciência.

Os controles estabelecidos sobre os estados de alteração da consciência seriam uma espécie de reação religiosa a todas as formas de individualismo libertário que se desenvolveram desde o final do século XVIII. A expansão do Estado de bem estar social seria a responsável por inscrever os anseios religiosos no campo político e transformar o dissidente farmacológico no novo herege da modernidade.

\section{Conclusão}

Procuramos apresentar neste artigo uma leitura da chave analítica da governamentalidade, enfatizando a necessidade de com- preender as formas pelas quais, em diferentes épocas e culturas, as pessoas que usam drogas tornam-se sujeitos. Apresentamos os deslocamentos realizados por Foucault nos debates feitos no Collège de France, que tentaram fazer dos sujeitos não meros objetos de governo ou de saberes, mas seres constituídos a partir de uma relação que envolve tecnologias de dominação (primeiro eixo) e o governo de si (segundo eixo). Para tanto é fundamental um novo olhar sobre as práticas discursivas produzidas em contexto brasileiro, por um lado, e sobre as dissidências farmacológicas que tais investidas encontram como respostas às tentativas normatizadoras.

\section{Referências}

BENCHIMOL, Jaime Larry. Dos micróbios aos mosquitos: febre amarela e revolução pasteuriana no Brasil. Rio de Janeiro: Fiocruz, 1999.

CASTRO, Hebe. História Social. In: CARDOSO, Ciro Flamarion; VAINFAS, Ronaldo (org). Domínios da História: ensaios de teoria e metodologia. Rio de Janeiro: Campus, 1997. p. 45-59.

\section{CARVALHO, Jonatas Carlos de. Regula- mentação e criminalização das drogas no} Brasil: a Comissão Nacional de Fiscalização de Entorpecentes. Rio de Janeiro: Multifoco, 2013.

CHALHOUB, Sidney. Cidade Febril: cortiços e epidemias na corte imperial. São Paulo: Companhia das Letras, 1996.

\section{COLLIER, Stephen J. Post-Soviet Social:} neoliberalism, social modernity, biopolitics. 
Princeton: Princeton University Press, 2011a.

COLLIER, Stephen J. Topologias do poder: a análise de Foucault sobre o governo político para além da 'governamentalidade'. Revista Brasileira de Ciência Política, Brasília (DF), n. 5, p.245-284, jan./jul.2011b.

COSTA, Jurandir Freire. Ordem médica e norma familiar. Rio de Janeiro: Graal, 1979.

EDLER, Flavio Coelho. As reformas do ensino médico e a profissionalização da Medicina na Corte do Rio de Janeiro: 18541884. 1992. Tese (Doutorado em História)Programa de Pós-Graduação em História Social da Universidade de São Paulo, São Paulo, 1992.

ESCOHOTADO, Antonio. Historia general de las drogas: incluyendo el apéndice Fenomenologia de las Drogas. Madrid: Espasa Calpe, 2008.

DELEUZE, Gilles. Foucault. São Paulo: Brasiliense, 2005.

FOUCAULT, Michel. O Cuidado com a Verdade. In: FOUCAULT, Michel. Ditos e escritos $\mathrm{V}$ : ética, sexualidade, política. Rio de Janeiro: Forense Universitária, 2012. p. 234-245.

FOUCAULT, Michel. O governo de si e dos outros. São Paulo: Martins Fontes, 2010. FOUCAULT, Michel. Segurança, território, população. São Paulo: Martins Fontes, 2008a.

FOUCAULT, Michel. Nascimento da biopolítica. São Paulo: Martins Fontes, 2008b.
FOUCAULT, Michel. Tecnologias de Si. Verve, São Paulo, n.6, p. 321-360, 2004. FOUCAULT, Michel. História da sexualidade 1:a vontade de saber. São Paulo; Rio de Janeiro: Graal, 2003.

FOUCAULT, Michel. O Sujeito e o Poder. In: DREYFUS, Hubert L; RABINOW, Paul. Michel Foucault - uma trajetória filosófica: para além do estruturalismo e da hermenêutica. Rio de Janeiro: Forense Universitária, 1995. p.231-249.

KAYE, Harley. Los historiadores marxistas britânicos. Zaragoza: Prensa Universitarias, 1989.

GROS, Frederic. Situação do Curso. In: FOUCAULT, Michel. A Hermenêutica do Sujeito. São Paulo: Martins Fontes, 2010.

LUZ, Madel Therezinha. A arte de curar versos a ciência das doenças: história social da homeopatia no Brasil. Rio de Janeiro: Graal, 1996.

MACHADO, Roberto; et al. Danação da norma: a medicina social e constituição da psiquiatria no Brasil. Rio de Janeiro: Edições Graal, 1978.

MILLER, Peter; ROSE, Nikolas. Governando o presente. São Paulo: Paulus, 2012.

RIBEIRO, Tiago Magalhães. Do você não pode ao você não quer: uma história da prevenção às drogas na educação. Curitiba: Appris, 2013.

RODRIGUES, Thiago. Política e Drogas nas Américas. São Paulo: Educ/Fapesp, 2004. 
ROSA, Pablo Ornelas. Drogas e a governamentalidade neoliberal: uma genealogia da redução de danos. Florianópolis: Insular, 2014.

SAYD, Jane Dutra. Mediar, medicar, remediar: aspectos da terapêutica na medicina ocidental. Rio de Janeiro: UERJ, 1998.

SANTOS, Fernando Sergio Dumas dos. Alcoolismo: Algumas Reflexões acerca do Imaginário de uma Doença. PHYSIS - Revista de Saúde Coletiva, Rio de Janeiro, v. 3, n. 2, p. 75-95, 1993.

SANTOS, Fernando Sergio Dumas dos. Alcoolismo: a invenção de uma doença. 1995. Dissertação-(História), Programa de PósGraduação em História pela Universidade de Campinas, Campinas (SP), 1995.

SANTOS, Fernando Sergio Dumas dos. Bêbados e Alcoólatras, Medicina e Cotidiano. In: NASCIMENTO Dilene Raimundo do; et al. (org). Uma história brasileira das doenças. Rio de Janeiro: Mauad X, 2006. v. 2. p. 64-91.

\section{SCHWARCZ, Lílian Moritz. O espetáculo} das raças: cientistas, instituições e questão racial no Brasil. São Paulo: Companhia das Letras, 1993.

SILVA, Luiza Lopes da. A questão das drogas nas relações internacionais: uma perspectiva brasileira. Brasília: Fundação Alexandre de Gusmão, 2013.

SOUZA, Jorge Emanuel Luz. Sonhos da diamba, controle do cotidiano: uma história da criminalização da maconha no Brasil republicano. 2012. Dissertação-(História),
Programa de Pós-Graduação em História da Universidade Federal Bahia, Salvador, 2012.

THOMPSON, Edward Palmer. A miséria da teoria ou um planetário de erros: uma crítica ao pensamento de Althusser. Rio de Janeiro: Zahar, 1981.

THOMPSON, Edward Palmer. A formação da classe operária inglesa: a árvore da liberdade. Rio de Janeiro: Paz e Terra, 1987. Tomo I. 